\section{APRENDIZAGEM FORMAL, NÃO FORMAL E INFORMAL: COMO CONDUTORES DE DOIS PARQUES NACIONAIS ESTABELECEM SEU TIROCÍNIO}

\author{
FORMAL, NON-FORMAL, AND INFORMAL LEARNING: HOW INSTRUCTORS OF \\ TWO NATIONAL PARKS ESTABLISH THEIR PROFESSIONAL PRACTICE
}

\author{
APRENDIZAJE FORMAL, NO FORMAL E INFORMAL: CÓMO LOS GUÍAS DE \\ DOS PARQUES NACIONALES ESTABLECEN SU PRÁCTICA PROFESIONAL
}

\author{
Marcial Cotes*, William das Neves Salles**, Alexandre Vinícius Bobato Tozetto**, \\ Juarez Vieira Nascimento**
}

\begin{abstract}
Palavras chave: Aprendizagem. Percepção. Natureza. Educação Física.

Resumo: 0 objetivo do estudo foi investigar as situações de aprendizagem profissional (formal, não formal e informal) de condutores de trilhas de longa duração atuantes em dois Parques Nacionais (PARNAs) brasileiros. Participaram do estudo descritivo-exploratório, com abordagem qualitativa dos dados, 79 condutores, sendo 49 não graduados e 30 graduados. Os procedimentos de análise de conteúdo foram empregados na apreciação das entrevistas semiestruturadas. Apesar da maioria dos investigados valorizar as situações formais, não formais e informais de aprendizagem, a aprendizagem informal com familiares, visitantes, demais condutores e a partir da reflexão sobre o próprio trabalho se sobressaiu sobre as demais. Os principais aprendizados nessas situações envolvem aspectos como questões climáticas, segurança dos visitantes, características específicas dos biomas e preservação ambiental. As evidências do estudo sinalizam a necessidade de os cursos de formação contemplarem mais oportunidades de práticas contextualizadas às exigências da prática profissional dos condutores, assim como períodos de estágio supervisionado por pares mais experientes.
\end{abstract}

Keywords: Learning. Perception. Nature. Physical Education.

Palabras clave: Aprendizaje. Percepción. Naturaleza. Educación Física.

Abstract: The study looked into professional - formal, non-formal, and informal - learning situations of long-trail instructors at two Brazilian national parks (PARNAs). As a descriptiveexploratory study with a qualitative data approach, it included 79 instructors from two PARNAs, of whom 49 had no college education while 30 were college graduates. Content analysis procedures were used to evaluate the semi-structured interviews. Most subjects value formal, non-formal, and informal learning situations, but informal learning from relatives, visitors, other drivers, and from reflection on the own work were more appreciated. Key learning in those situations involves aspects such as climate issues, visitor safety, biome-specific characteristics, and environmental preservation. Evidence from the study indicates the need for schools to include more practice opportunities for instructors that are more contextualized in terms of professional practice requirements, as well as periods of practicum supervised by more experienced peers.

Resumen: El objetivo del estudio fue analizar las situaciones de aprendizaje profesional (formal, no formal e informal) de guías de senderismo de larga duración que actúan en dos Parques Nacionales (PARNAs) brasileños. Participaron del estudio descriptivo exploratorio, con abordaje cualitativo de los datos, 79 guías, de los cuales 49 no graduados y 30 graduados. Los procedimientos de análisis de contenido se utilizaron para analizar las entrevistas semiestructuradas. A pesar de que la mayoría de los investigados valora las situaciones formales, no formales e informales de aprendizaje, el aprendizaje informal con familiares, visitantes, demás guías y a partir de la reflexión sobre el propio trabajo se destacó. Los principales aprendizajes en estas situaciones involucran aspectos como cuestiones climáticas, seguridad de los visitantes, características específicas de los biomas y preservación ambiental. Las evidencias del estudio señalan la necesidad de que los cursos de formación contemplen más oportunidades de prácticas contextualizadas a las exigencias de la práctica profesional de los guías, así como períodos de práctica supervisados por pares más experimentados.
*Universidade Estadual de Santa Cruz (UESC). Ilhéus, BA, Brasil.

E-mail: mcotes@uesc.br

**Universidade Federal de Santa Catarina. Florianópolis, SC, Brasil. E-mail: williamdnsalles@gmail.com; alexandrebobato@ hotmail.com; juarez.nascimento@ufsc.br

Recebido em: 28-07-2017 Aprovado em: 24-10-2017

DOI: http://dx.doi.org/10.22456/1982-8918.75313 (c) (i) () Licence 


\section{INTRODUÇÃO}

A condução de visitantes em Unidades de Conservação (UC) é uma atividade que foi regulada no Brasil pelo Ministério do Turismo (MT) e Instituto Chico Mendes de Conservação da Biodiversidade (ICMBio), e que deve ser exercida por profissional cadastrado no órgão gestor e capacitado especificamente para esta função (BRASIL, 2014a; BRASIL, 2016). O condutor pode ser considerado um "[...] profissional da área do turismo e auxiliador da sensibilização e conservação ambiental, capaz de conduzir visitantes em diversos atrativos (sítios) turísticos naturais de sua localidade de ação - protegidos ou não" (RIBAS; HICKENBICK, 2012, p. 147).

Os Parques Nacionais (PARNAs) são uma das alternativas para aqueles que procuram caminhadas em Trilhas de Longa Duração (TLD) em contato com a natureza. Embora alguns PARNAs permitam a entrada de visitantes sem a companhia do condutor, esse profissional pode oferecer suporte em questões como história da unidade, segurança, educação ambiental e cultura, o que pode propiciar uma experiência hedonista bem-sucedida para aqueles que buscam TLD em UC (RIBAS; HICKENBICK, 2012; PEREIRA; SILVA; SILVA-JUNIOR, 2015; CANTO-SILVA; SILVA, 2017). Além disso, Collins e Collins (2012) comentam que ele explora a natureza como meio para o desenvolvimento pessoal e que sua prática apresenta características educacionais.

Considerando a necessidade de os condutores dominarem conhecimentos didáticopedagógicos de ordem conceitual, procedimental e atitudinal (SCHWARTZ; CARNICELLI FILHO, 2006; PAIXÃO, 2013; 2015), assim como o papel dos cursos de formação (PEREIRA; SILVA; SILVA-JUNIOR, 2015) e do licenciamento (BRASIL, 2016; CANTO-SILVA; SILVA, 2017) no processo de desenvolvimento desses profissionais, desperta-se a necessidade de investigar como esses conhecimentos são aprendidos.

A literatura sobre aprendizagem profissional em Educação Física (EF) apresenta-se em crescimento acelerado (GILBERT; TRUDEL, 2001; TRUDEL; CULVER; RICHARD, 2016), devido à importância do profissional de EF na dinâmica de contextos específicos. Assume-se que a aprendizagem é um processo que ocorre ao longo da vida do indivíduo a partir da atribuição de significados às diferentes experiências que vivencia, o que pode resultar na reconfiguração contínua da identidade biográfica do sujeito (JARVIS, 2013; 2015). Dentre as oportunidades de aprendizagem profissional, destacam-se as situações formais, as não formais e as informais (NELSON; CUSHION; POTRAC, 2006). As situações formais caracterizam-se por apresentar programas educacionais de longa duração, com frequência obrigatória, currículos padronizados e exigência de avaliações institucionais para atingir a certificação (por exemplo, os cursos de graduação). Enquanto que a aprendizagem nas situações não formais é adquirida por meio das oportunidades de participar de conferências, workshops, congressos, simpósios e cursos de pequena duração, muitas vezes organizados por associações de moradores e pelos próprios condutores, as situações informais costumam ocorrer fora de instituições educacionais (como universidades e escolas), com base nas motivações do próprio indivíduo, a partir das relações sociais e culturais estabelecidas, seja no âmbito da família ou no meio social onde está inserido (NELSON; CUSHION; POTRAC, 2006; MALLETT et al., 2009; JARVIS, 2013; 2015).

Estudos realizados no âmbito do treinamento esportivo têm indicado que os treinadores costumam atribuir maior significância às aprendizagens informais em detrimento das formais e não formais, pois estas tendem a não estar completamente alinhadas aos interesses e 
às necessidades específicas dos participantes (RAMOS; BRASIL; GODA, 2012; RAMOS et al., 2014; STOSZKOWSKI; COLLINS, 2016). A formação de profissionais atuantes com atividades na natureza apresenta problemática semelhante, pois as capacitações parecem não acompanhar o ritmo de crescimento das atividades existentes e das que surgem, não atendendo às imponderabilidades do contexto e, consequentemente, não exercendo impacto significativo para habilitar o profissional a lidar eficazmente com as demandas de sua atividade (PAIXÃO; TUCHER, 2010; PAIXÃO, 2013; 2015).

Com a intenção de identificar a realidade específica dos condutores atuantes em UC no que tange à aprendizagem profissional, bem como de fornecer informações relevantes aos responsáveis pela organização de oportunidades de formação inicial e continuada no âmbito das atividades na natureza, o objetivo deste estudo foi investigar as situações de aprendizagem profissional (formal, não formal e informal) de condutores de TLD atuantes em dois PARNAs brasileiros.

\section{PROCEDIMENTOS METODOLÓGICOS}

\subsection{Caracterização do estudo}

A investigação caracteriza-se como descritivo-exploratória (GIL, 2008), com abordagem qualitativa dos dados (FLICK, 2009). As pesquisas descritivo-exploratórias procuram analisar as opiniões das pessoas ou grupos sociais e situações de desempenho profissional na prática, bem como desenvolver, elucidar e alterar concepções e ideias, por meio da elaboração de pressupostos que poderão incidir em estudos posteriores (GIL, 2008).

A abordagem qualitativa reconhece a complexidade e a subjetividade presente nos fenômenos sociais, motivo pelo qual busca evitar a medição e a quantificação dos fenômenos, assim como o desenvolvimento de planos de pesquisa que permitam generalizações e a formulação de leis gerais. Em vez disso, a abordagem qualitativa busca interpretar a situação investigada a partir do olhar da complexidade e da consideração às perspectivas dos indivíduos investigados, o que permite a adoção de postura mais reflexiva do investigador no processo de construção da pesquisa (FLICK, 2009). No presente estudo, esta abordagem foi empregada para descrever as relações empreendidas entre condutores, as representações sociais, as opiniões sobre a profissão e as interpretações dos condutores acerca de seu trabalho de condução em TLD em PARNAs.

\subsection{Seleção dos parnas e dos participantes da pesquisa}

A escolha do Parque Nacional da Serra da Capivara (PNSC) para a coleta de dados se justifica pela excelência de sua estrutura, assim como por sua localização no sudoeste do Piauí (região do semiárido brasileiro), pela sistematização de cursos de formação de condutores que acontece na unidade desde 1993, pela presença de portaria do ICMBio com o registro dos condutores que atuam na UC (BRASIL, 2014b) e obrigatoriedade do visitante ser acompanhado por este profissional. O Parque Nacional do Caparaó (PNC), por sua vez, foi selecionado por contrapor a situação descrita no PNSC, ou seja, localiza-se entre os estados do Espírito Santo e Minas Gerais, não possui portaria do ICMBio para registro dos condutores credenciados nem obrigatoriedade da presença de condutor durante as atividades de visitação. 
Como critério para definir os condutores do PNSC participante do estudo, utilizou-se a Portaria do ICMBio no 8 (BRASIL, 2014b), a qual lista 59 profissionais devidamente registrados. Considerando que, destes, seis não atuam com TLD, dois não residem mais na região e um deixou de atuar profissionalmente, foram selecionados intencionalmente 50 . Neste universo de 50 condutores do PNSC, 80\% ( $n=40)$ foram entrevistados por aceitarem participar da investigação. No PNC, por não haver obrigatoriedade de acompanhamento dos visitantes por condutor e pela inexistência de portaria de cadastramento do ICMBio, utilizou-se lista atualizada de 46 profissionais credenciados na UC. Destes, foram entrevistados $84,8 \%(n=39)$ dos condutores.

\subsection{Instrumento de coleta de dados}

As informações foram levantadas a partir de entrevista semiestruturada aplicada aos condutores do PNC e do PNSC. A entrevista foi organizada a partir dos seguintes temas geradores: informações sociodemográficas dos condutores; nível de formação dos condutores; saberes dos condutores para atuar em TLD; origem dos conhecimentos adquiridos na condução. De acordo com Flick (2009), os entrevistados normalmente possuem um conjunto complexo de conhecimentos sobre o tema sob estudo, os quais podem ser expressos espontaneamente ao responder às questões de uma entrevista. Neste sentido, a entrevista semiestruturada permite mesclar a utilização de questões fechadas e abertas, que permitem determinada flexibilidade ao investigador no processo de estruturação das questões e, consequentemente, a obtenção de distintos níveis de informação sobre o tópico abordado.

\subsection{Procedimentos para coleta de dados}

Inicialmente, o projeto de pesquisa foi submetido ao Comitê de Ética de uma Instituição Federal de Ensino Superior do Brasil, sendo aprovado pelo parecer no 1.315.275. Na sequência, foram obtidos a autorização para atividades com finalidade científica (n- 49.700-1) e o código de autenticação (14.226.816) no ICMBio para, depois, realizar o contato com os gestores das UC com o propósito de apresentar e tirar dúvidas sobre a pesquisa a ser conduzida. Com o aval dos gestores, os condutores foram contatados e convidados a participar voluntariamente da pesquisa entre novembro de 2015 e janeiro de 2016, nas cidades de Coronel José Dias e São Raimundo Nonato (PNSC); e Alto Caparaó e Patrimônio da Penha (PNC).

Os condutores que concordaram em participar voluntariamente do estudo leram e assinaram o Termo de Consentimento Livre e Esclarecido. As entrevistas ocorreram no interior e/ou no entorno do PARNA de atuação de cada condutor e foram realizadas individualmente, com o suporte de um gravador digital para a coleta das informações.

\subsection{Tratamento e análise dos dados}

as entrevistas foram gravadas em áudio, transcritas literalmente com auxílio do programa Microsoft Word e armazenadas em microcomputador. Na transcrição das 79 entrevistas considerou-se a verbalização oral e gramatical, com objetivo de afiançar o conteúdo na integra. Posteriormente, as transcrições foram enviadas para todos os condutores por meio de correio eletrônico para correção, inclusão e/ou supressão de texto, com a intenção de realizar sua validação comunicativa (FLICK, 2009). 
Em seguida, as entrevistas foram inseridas no programa QSR NVivo versão 9.2, com o objetivo de proceder à análise de conteúdo de acordo com os procedimentos sugeridos por Bardin (2010, p. 121): pré-análise; exploração do material; tratamento dos resultados; inferência e interpretação. Na pré-análise, as entrevistas foram organizadas no programa a partir dos temas geradores (estabelecidos a priori), e possíveis unidades de significado foram definidas a partir de leituras exaustivas das transcrições. Na etapa de exploração do material, procedeu-se à codificação das transcrições brutas em representações/nós de conteúdo e à confirmação das unidades de significado encontradas na etapa anterior. Na fase de tratamento dos dados foram realizadas a contagem da frequência das unidades de significado e a consequente organização dos resultados.

A confirmação da representatividade das categorias (PATTON, 1990) foi estabelecida a posteriori, após a exaustividade de análise e a discussão com dois pesquisadores: um com vasta experiência em pesquisa qualitativa e em formação profissional na área de $E F$, e outro com amplo conhecimento na área de Ciências Ambientais, com ênfase em gestão de áreas protegidas e análise de estratégias de conservação.

As informações quantitativas (dados de caracterização) foram, inicialmente, inseridas e categorizadas em planilha do programa SPSS Statistics (versão 21.0), sendo posteriormente analisadas a partir de recursos da estatística descritiva (frequência absoluta e relativa). Os condutores formados ou que estavam cursando a graduação (independentemente da área) no momento da coleta de dados foram incluídos dentro da categoria "aprendizagem formal".

\section{RESULTADOS E DISCUSSÃO}

As situações de aprendizagem profissional relatadas pelos condutores (Tabela 1) revelaram que a maioria dos condutores investigados não está cursando ou não concluiu curso de nível superior. Quanto à área de formação universitária dos graduados do PNSC, ressaltamse os cursos de Geografia $(n=6)$, História $(n=5)$, Pedagogia $(n=3)$, Ciências Naturais $(n=2)$ e Biologia ( $n=2)$. Dos oito condutores graduados do PNC, três cursaram Turismo.

Tabela 1 - Situações de aprendizagem profissional considerando a formação dos condutores.

\begin{tabular}{|c|c|c|c|c|c|}
\hline & \multirow[b]{2}{*}{ Situações de Aprendizagem } & & \multicolumn{3}{|c|}{ PARNA } \\
\hline & & & $\begin{array}{l}\text { PNSC } \\
(n=40)\end{array}$ & $\begin{array}{c}\text { PNC } \\
(n=39)\end{array}$ & $\begin{array}{c}\text { Total } \\
(\mathrm{n}=79)\end{array}$ \\
\hline \multirow{2}{*}{ Formal } & \multirow{2}{*}{ Graduação } & Não & $18(45,0)$ & $31(79,5)$ & $49(62,0)$ \\
\hline & & $\operatorname{Sim}$ & $22(55,0)$ & $8(20,5)$ & $30(38,0)$ \\
\hline \multirow{2}{*}{ Não formal } & \multirow{2}{*}{ Curso específico de condutor } & Não & $1(2,5)$ & $8(20,5)$ & $9(11,4)$ \\
\hline & & Sim & $39(97,5)$ & $31(79,5)$ & $70(88,6)$ \\
\hline \multirow{6}{*}{ Informal } & \multirow{2}{*}{ Aprendizagem com visitantes } & Não & $0(0,0)$ & $4(10,3)$ & $4(5,1)$ \\
\hline & & Sim & $40(100,0)$ & $35(89,7)$ & $75(94,9)$ \\
\hline & \multirow{2}{*}{ Aprendizagem com condutores } & Não & $0(00,0)$ & $6(15,4)$ & $6(7,6)$ \\
\hline & & Sim & $40(100,0)$ & $33(84,6)$ & $73(92,4)$ \\
\hline & \multirow{2}{*}{ Reflexão sobre o próprio trabalho } & Não & $2(5,0)$ & $4(10,3)$ & $6(7,6)$ \\
\hline & & Sim & $38(95,0)$ & $35(89,7)$ & $73(92,4)$ \\
\hline
\end{tabular}


Quanto às situações de aprendizagem não formal, observa-se que a maioria dos condutores investigados, independentemente do PARNA, já realizou o curso de capacitação para condutor de visitantes. Um aspecto a ser destacado é que, enquanto este curso foi realizado por todos condutores graduados, nove não graduados nunca o realizaram. De acordo com 0 artigo 13 da Instrução Normativa no 2 do ICMBio, os profissionais que ainda não possuem 0 curso de condutor devem se capacitar até maio de 2017 para receber a autorização de uso na prestação do serviço de condução de visitantes em UC federal (BRASIL, 2016).

Finalmente, a análise das situações informais de aprendizagem indica que a maior parte dos condutores investigados revelou aprender pela própria experiência profissional, por meio da reflexão sobre o próprio trabalho. Além disso, a aprendizagem com pares e com os próprios visitantes dos PARNAs foi identificada em quase todos os profissionais investigados.

\subsection{Aprendizagem formal}

Os relatos dos condutores acerca das situações formais de aprendizagem contemplam questões ambientais e destacam a importância da disciplina de didática, conforme segue:

$\mathrm{Na}$ realidade, a condução se torna uma aula, e nós temos muitos turistas que vêm aqui com caráter acadêmico, que são as excursões escolares. Então, essas metodologias de técnica de aprendizagem, técnicas de ensino de didática, e essas estruturas que 0 curso de Pedagogia oferece para gente na graduação, com certeza nós aplicamos no trabalho de condutor (Condutor 52/PNSC - graduado).

Eu acho que me auxilia porque na disciplina de Didática algumas ações e atos que trabalhamos dentro da sala de aula nós levamos para o trabalho de condução. 0 modo de se comportar, a maneira de se dirigir ao turista de falar, de se relacionar e de explicar ajuda bastante (Condutor 55/PNSC - graduado).

Nós temos uma disciplina, que se chama Sustentabilidade e Cidadania, e está sendo muito bom, porque a gente vai interagir com o meio e tentar fazer que este meio ambiente não seja tão danificado. Como eu trabalho em um parque nacional, uma área protegida que precisa de vários cuidados, estes cuidados vão ser transmitidos para os visitantes, e a gente precisa estar atento a isto. Eu me identifiquei muito com esta matéria (Condutor 73/PNSC - graduado).

As situações de aprendizagem formal, nomeadamente a realização de cursos de graduação, foram fundamentais para o desenvolvimento de habilidades didático-pedagógicas dos condutores 52, 55 (psicopedagogo) e 73 (licenciado em Ciência da Natureza) do PNSC, o que também foi identificado em investigação realizada por Paixão e Tucher (2010). Em investigação realizada com 46 bacharéis em EF, Santos et al. (2015a) encontraram que a presença de disciplinas sobre esportes de aventura e na natureza pode contribuir para a percepção de maiores competências profissionais, bem como oportunizar a visualização deste âmbito do mercado de trabalho em EF. Além dos aspectos mais técnicos relacionados à profissão e ao mercado de trabalho, a formação inicial em EF também pode estimular o desenvolvimento de hábitos socioambientais adequados pelos estudantes (MARINHO; SANTOS, 2014), o que revela sua importância para a formação ético-moral do futuro condutor e seu potencial enquanto situação de aprendizagem desses profissionais.

Para que a aprendizagem se torne mais significativa aos estudantes-condutores, 0 período de formação inicial necessita simular ações que possam ocorrer na prática (JARVIS, 
2013). Além disso, seria importante aliar à organização do processo pedagógico incorporado pelo professor, com base na pesquisa, ensino e extensão de modo integrado, com o intuito de desenvolver os conteúdos, com os estudantes, por meio da valorização não apenas dos esportes, mas das demais práticas corporais presentes na cultura humana (DOMINGUES; KUNZ; ARAÚJO, 2011).

Um aspecto a destacar é que nenhum dos condutores de TLD investigados no presente estudo realiza ou realizou curso de graduação em EF (licenciatura ou bacharelado). Tais resultados diferem dos resultados de pesquisas desenvolvidas no estado de Minas Gerais por Paixão e Tucher (2010) e Paixão (2013), em que 71\% dos instrutores de esporte de aventura tinham curso superior e, destes, $43 \%$ eram formados na área de EF. $O$ âmbito das atividades praticadas na natureza, de fato, se apresenta de maneira complexa, congregando interesses não apenas da EF, mas também de áreas como o Turismo e as Ciências da Natureza. Sobre este aspecto, Pimentel (2013, p. 697) chama a atenção para a disputa de poder existente nas modalidades de aventura: "Ao dizer, por exemplo, se o trekking é turismo ou esporte, se legaliza a quem o profissional de aventura deve sujeitar-se [...] e, consequentemente, quais normalizações irá seguir". Apesar disso, acredita-se que a EF pode contribuir para a formação profissional dos condutores de atividades na natureza em PARNAs espalhados pelo território brasileiro, especificamente no que tange a aspectos como: técnicas envolvidas na prática de modalidades de aventura; preparo psicológico para lidar com grupos de pessoas em situações de aprendizagem; emoções e riscos; componentes didático-pedagógicos presentes igualmente em circunstâncias de aprendizado; utilização de estilos de ensino; e educação ambiental (SCHWARTZ; CARNICELLI FILHO, 2006; PAIXÃO; TUCHER, 2010; PAIXÃO, 2013).

\subsection{Aprendizagem não formal}

a análise das situações não formais de aprendizagem revela que alguns condutores valorizam e consideram os cursos de capacitação de condutores importantes em sua formação para a prática profissional, contribuindo para evitar impactos ambientais, gerar maior conforto e mais informações aos visitantes, saber como proceder em casos de visitantes perdidos e utilização dos primeiros socorros:

0 que a gente percebeu no curso é que o serviço de condução deixa o condutor bem qualificado e a gente consegue minimizar muitos riscos. 0 principal é o cara não se perder. $O$ segundo podemos classificar como impacto ambiental. 0 guia bem-capacitado não vai permitir que 0 grupo deixe lixo, que estrague a trilha ou estrague qualquer coisa da fauna e flora, prejudicando desta forma o meio ambiente (Condutor 3/PNC - graduado).

O lixo tem que colocar em sacola e voltar com ele. Isto a gente aprendeu no curso. Depois do curso eu modifiquei a orientação ao turista sobre o calçado, roupa e equipamento, para subir no pico sem exagero (Condutor 14/PNC - não graduado).

Ao participar dos cursos você percebe que tem muita coisa, além da parte estrutural e do conteúdo curricular. Tem muita coisa que você atrela ao convívio dos seus antepassados (Condutor 52/PNSC - graduado).

No entanto, alguns condutores também destacaram a insuficiência ou o caráter superficial/complementar desses cursos, ressaltando a importância da experiência prática na atuação profissional: 
O curso de primeiros socorros não foi suficiente. Pelo tempo que foi e também pelas aulas que não foram muitas, a gente fez um curso de longa duração, mas era só uma vez na semana, só no final de semana. Eu acho que um curso de primeiros socorros é muito importante para trabalhar no parque... acho que poderia ser um curso mais voltado só para aquilo ali mesmo que temos no parque, mais aprofundado (Condutor 49/PNSC - não graduado).

Eu cresci acompanhando o crescimento do parque nacional. Este conhecimento de berço vale muito, e se você tiver interesse os cursos ajudam muito você a pegar os conhecimentos que você não tem (Condutor 56/PNSC - não graduado).

Também foi possível identificar, como situações de aprendizagem não formal, cursos que apresentam relação direta com as demandas de cada PARNA investigado. Assim, podem ser citados, para o PNC, dois cursos que aparecem com mais frequência: primeiros socorros (24) e brigada contra incêndio (11). No PNSC, observou-se maior diversidade de cursos, destacandose: primeiros socorros (38), arqueologia (26), geologia (22), conservação de pinturas rupestres (16), guarda-parque (9) e inglês e/ou francês (9). Neste sentido, é pertinente ressaltar que, na maioria dos relatos para ambas UC, o curso de primeiros socorros foi ministrado de forma superficial, como parte integrante dos cursos de condutor de visitantes.

Ao considerar o conceito de aprendizagem não formal presente na literatura sobre treinamento esportivo (NELSON; CUSHION; POTRAC, 2006; RAMOS; BRASIL; GODA, 2012; TRUDEL; CULVER; RICHARD, 2016), que compreende que esse tirocínio é adquirido por meio de conferências, workshops, congressos, simpósios e, neste caso, os cursos de capacitação de condutores, observa-se a relevância que essas modalidades de formação têm para aprimorar a atuação desses profissionais dentro das UC investigadas. Sobre as questões educacionais que envolvem o meio ambiente e políticas públicas, Vasconcellos et al. (2009) ressaltam que a realização de cursos específicos (como as conferências realizadas sobre essa temática) pode fortalecer ações que visem à articulação e interlocução entre as pessoas envolvidas com a Educação Ambiental. Em investigação realizada por Santos et al. (2015b), por sua vez, identificou-se que os participantes de um projeto de ensino sobre questões socioambientais destacaram alguns aspectos, como sua relevância para a integração entre estudantes de diferentes cursos, a socialização entre os membros da sua organização, os novos conhecimentos adquiridos e a disseminação de valores relacionados ao meio ambiente.

A situação de aprendizagem não formal, então, pode preencher lacunas na formação de condutores proporcionadas pelos cursos de graduação em EF, os quais normalmente apresentam-se generalistas e têm como propósito atender as áreas de saúde, esporte, lazer e, por isso, podem não apresentar tempos e espaços específicos destinados às atividades na natureza (CORRÊA, 2008; DOMINGUES; KUNZ; ARAÚJO, 2011; VAZ et al., 2017). Além disso, os cursos de curta duração podem proporcionar aos não graduados maior conscientização sobre a sustentabilidade do local onde se desenvolvem as atividades, bem como sobre questões éticas e sobre atendimento especial às diferentes necessidades apresentadas pelos visitantes (CORRÊA, 2008).

\subsection{Aprendizagem informal}

Aanálise dos relatos dos condutores permitiu identificar determinadas situações informais de aprendizagem profissional que aparecem como significativas, a saber: aprendizagem na família, aprendizagem com condutores mais experientes e aprendizagem durante o trabalho, a 
partir da reflexão sobre a própria prática e da conversa com outros condutores, com visitantes e com guarda-parques.

Os relatos a seguir elucidam a importância dos familiares para a própria aprendizagem profissional dos condutores investigados:

Meu pai foi condutor. Ele passou isso tudo para mim sobre lanche, sobre agasalho, sobre lanterna. Você pode sair para a montanha com o tempo aqui embaixo aberto, tudo limpinho, mas lá na montanha não é igual aqui, lá você tem que levar capa, agasalho, lanterna... lá você não encontra nada (Condutor 12/PNC - não graduado).

A parte estrutural do conteúdo curricular que você aprende no curso de condutor de visitantes é a parte básica que você tem que saber. Mas o que abrilhanta o trabalho é exatamente o conhecimento popular que eu aprendi com o meu pai, que o meu pai aprendeu com o pai dele o meu avô. [...] É como eu te falei, digamos assim, a parte burocrática o curso de condutor lhe fornece, tipo: quantas espécies, a questão geológica (Condutor 52/PNSC - graduado).

Fui crescendo e minha avó me mostrou o valor de não atirar nos passarinhos com estilingue para que a gente pudesse preservar, pois ela dizia que no outro dia ele iria voltar. [...] 0 cuidado que meus avós tinham com os animais domésticos e silvestres teve resultado, pois quando nós encontramos em uma guarita do parque jacu, cotia ou caititu, é porque nós respeitamos aquele espaço (Condutor 73/PNSC - graduado).

O aprendizado na família, presente nas declarações dos condutores acima, foi percebido na maioria dos relatos dos 79 entrevistados. Tais dados indicam o quanto essa atividade profissional vem sendo transmitida de geração a geração, semelhante ao que Jarvis (2013; 2015) denomina de conhecimentos tácitos estabelecidos no decorrer da vida e que fazem parte da socialização primária, envolvidos na cultura familiar.

Os relatos dos condutores C16, C18 e C55 revelam que esse aprendizado não se deu exclusivamente na família, mas foi complementado com a aprendizagem no contato com os mais experientes, na prática. Outro aspecto característico nos relatos dos condutores do PNC e no PNSC foi a utilização da área das UC como pasto para animais e para a agricultura familiar, respectivamente. Especificamente, essas falas indicam experiências práticas anteriores à implantação das UC, o que tem contribuído para a intervenção no trabalho de condução.

Aprendi com os mais antigos a questão da previsão do tempo. 0 que eles chamam de canoas, que dão por cima das montanhas, são nuvens mais escuras em forma de listas. Se você vê essas canoas, pode contar que vai chover (Condutor 16/PNC - não graduado).

Cara, tem um senhor que a gente acompanhava até lá em cima, ele tinha animais na área que ficava no parque. Íamos para ajudar a procurar e olhar os animais. Em relação ao tempo ele passou uma noção, os pontos de referência que a gente pode seguir, em relação ao frio para andar prevenido, para não passar "perrengue" lá em cima (Condutor 18/PNC - não graduado).

Sobre o bioma Caatinga, aprendemos muito com os mais velhos em relação ao nome de árvores, de animais, o melhor momento do dia para visualizar os animais, como você se defende dos animais, as plantas que são utilizadas para enfermidades, como o pau de rato - que é bom para dor de barriga. Em relação aos bandos de macacos, você deve observar bem porque sempre vai ter um, como os mais velhos contam, que vai ficar num local mais alto para preservar os que estão se alimentando. É como se fosse um vigia ou guarda (Condutor 55/PNSC - graduado). 
As situações de aprendizagem experienciadas no próprio trabalho na companhia de indivíduos mais experientes revelam a valorização do saber experiencial para a construção do conhecimento profissional (GILBERT; TRUDEL, 2001), que no caso do presente estudo envolve aspectos do clima, dos hábitos dos animais e da flora, todos explorados por alguns condutores investigados.

Com a implantação dos PARNAs, os conhecimentos advindos da família para a prática da caça são transformados e modificados em prol da conservação da natureza, a partir da condução de visitantes. Embora a aprendizagem com os mais experientes tenha permitido experienciar vivências que os mais novos não tiveram, aumentando os sentimentos de pertencimento e a valorização da cultura local, a aprendizagem decorrente da prática é preponderante, ao proporcionar determinada segurança aos condutores ao lidarem com situações similares. Esse repertório diversificado de situações de aprendizagem profissional encontra correspondência com a teoria da aprendizagem ao longo da vida de Jarvis (2013; 2015), bem como com a descrição de profissional reflexivo proposta por Shön (2008).

O repertório diversificado de situações de aprendizagem profissional na família, com os mais experientes e na prática, manifesta-se com clareza nas falas a seguir:

Aprendi muito com o meu irmão William', com o Alexandre e com o Juarez, que são caras que a gente valoriza. Tem condutores que são historiadores, e a gente aprende muito com esses caras e com o turista também. No decorrer da sua profissão, na prática, você vai se aperfeiçoando e se tornando um ótimo condutor. $E$ do mesmo jeito que eu aprendo com os outros, eu sei que os condutores mais novos aprendem comigo. [...] Quanto mais eu trabalho, mais eu aprendo. Eu aprendo mais na prática porque você vai aprendendo a se expressar melhor (Condutor 44/PNSC - não graduado).

Tem um cara aqui que é professor formado em Biologia, e quando a gente sai com ele a gente aprende muito. Esse aprendizado que você tem a cada passeio é importante. Uma vez conduzi um cara que era biólogo e subimos numa vista panorâmica. Lá em cima ele me mostrou como eram os períodos chuvosos através das rochas, quando choveu mais ou menos neste período (Condutor 45/PNSC - não graduado).

A gente nunca é autossuficiente, sempre tem alguma coisa para aprender, até porque a gente recebe muito geólogo e pessoas que são conhecedoras das áreas. Às vezes eu não preciso falar, deixo que eles expliquem para a gente ao invés da gente dar aula... recebemos aula dentro do parque. [...] Eu observo muito os meus colegas porque você descarta o que acha que não é certo ou ruim, e traz para você as coisas bacanas (Condutor 51/PNSC - não graduado).

As respostas dos condutores C44 e C45 demonstram que os profissionais admitem aprender com os outros condutores mais experientes durante a prática, e que esse aprendizado na prática, ou no decorrer da vida, constitui-se como parte substancial deste tirocínio defendido por Jarvis $(2013 ;$ 2015).

As informações analisadas nas 79 entrevistas dos condutores investigados apontam que a aprendizagem informal, a partir da observação na prática, repercute no desempenho profissional dos condutores, além de reforçar os níveis de retenção da aprendizagem apresentados por Piletti (1991, p. 156), que afirma que aprendemos: " $10 \%$ do que lemos; $20 \%$ do que escutamos; $30 \%$ do que vemos; $50 \%$ do que vemos e ouvimos; $70 \%$ do que ouvimos e logo discutimos; $90 \%$ do que

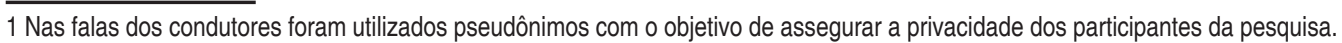


ouvimos e logo realizamos". Assim, os achados deste estudo demonstram que as observações e 0 compartilhamento de informações pelos condutores investigados resultam em maior experiência e na incorporação de novos aprendizados, permitindo que se tornem ótimos profissionais (Condutor 44/PNSC). Além disso, os achados do presente estudo assemelham-se aos encontrados em investigações realizadas junto a instrutores de atividades de aventura (SCHWARTZ; CARNICELLI FILHO, 2006; VAZ et al., 2017), nos quais se identificou que a experiência profissional parece aumentar a confiança desses profissionais pelo fato de desenvolverem, ao longo dos anos de prática, determinadas competências necessárias à atuação com atividades na natureza.

Neste sentido, Schön (2008) defende a importância de pensar o que se faz, enquanto se faz. Ou seja, o profissional reflexivo deve ser capaz de refletir durante sua prática, pois aprende por meio do que denomina reflexão na ação ao se deparar com situações que envolvem incertezas, singularidades e conflitos. Além disso, propõe a aprendizagem baseada no fazer, a qual potencializa a aquisição de talentos artísticos essenciais para manifestar competência em zonas indeterminadas da prática (SCHÖN, 2008).

\section{CONSIDERAÇÕES FINAIS}

Os resultados deste estudo permitem apontar que a aprendizagem para o trabalho de condução de visitantes em PARNAs tem como sustentáculos as situações formal, não formal e informal. Os condutores entrevistados destacaram o papel preponderante da aprendizagem na prática (de caráter informal) para seu desempenho profissional nos PARNAs. Isto elucida a presença de um repertório complexo de vivências, que cria diversidade de aprendizagens construídas a partir da formação em diversos níveis e, principalmente, nas inter-relações estabelecidas nos âmbitos familiar e profissional.

Os resultados do estudo também sinalizam a necessidade de adaptações na maneira como os cursos de formação de condutores devem ser estruturados, independentemente da localização do PARNA, de modo a contemplar mais situações e vivências práticas contextualizadas às exigências da prática profissional, assim como períodos de estágio supervisionado por outro condutor mais experiente. Neste sentido, acredita-se ser essencial a realização de estudos que investiguem as necessidades formativas desses profissionais.

A EF, especificamente, necessita empreender esforços para viabilizar, nas disciplinas já existentes nas estruturas curriculares da formação inicial (bacharelado e licenciatura), conteúdos de ensino que possam contribuir para a formação desses futuros profissionais, abordando aspectos como técnicas de determinadas atividades praticadas em UC, preparo psicológico para lidar com a aprendizagem, a emoção e o risco, além dos componentes didático-pedagógicos envolvidos no processo de gestão de pessoas (visitantes) nesse tipo de ambiente.

Reconhecem-se as limitações presentes nesta investigação ao optar por estudar somente dois PARNAs de um universo de 72 existentes no território nacional, o que sugere cautela e contextualização na interpretação dos resultados encontrados. Não obstante, pode-se dizer que o trabalho de condução em PARNAs, no território brasileiro, apresenta características que insinuam a ocorrência de aprendizagens ao longo da vida, com destaque para a aprendizagem adquirida antes do início da atuação profissional, por meio de contato com outros condutores, com pessoas mais velhas, assim como pela própria convivência com familiares. 


\section{REFERÊNCIAS}

BARDIN, Laurence. Análise de conteúdo. São Paulo: Edições 70, 2010.

BRASIL. Ministério do Meio Ambiente. Instituto Chico Mendes de Conservação da Biodiversidade. Estabelece normas e procedimentos para o exercício da atividade de condução de visitantes em unidades de conservação federais. Instrução normativa no2, Brasília, DF, 3 de maio, 2016.

BRASIL. Ministério do Turismo. Portaria n⿳27, de 30 de janeiro. Define as atividades de condutor e guias. Brasília, DF, 2014a.

BRASIL. Ministério do Meio Ambiente. Instituto Chico Mendes de Conservação da Biodiversidade. Condutores credenciados do Parque Nacional Serra da Capivara. Brasília, DF, Portaria $n^{\circ} 8$ de 09 de abril, 2014b.

CANTO-SILVA, Celson Roberto; SILVA, Jordana Santos. Panorama da visitação e da condução de visitantes em Parques brasileiros. Revista Brasileira de Pesquisa em Turismo, v.11, p. 365386, 2017.

COLLINS, Loel; COLLINS, Dave. Conceptualizing the adventure-sports coach. Journal of Adventure Education and Outdoor Learning, v.12, n.1, p. 81-93, 2012.

CORRÊA, Evandro Antônio. Formação do profissional de Educação física no contexto das atividades físicas de aventura na natureza. 2008, 147 f. Dissertação (Mestrado em Educação Física) - Instituto de Biociências, Universidade Estadual Paulista, Rio Claro, 2008.

DOMINGUES, Soraya Corrêa; KUNZ, Elenor; ARAÚJO, Lísia Costa Gonçalves. Educação Ambiental e Educação Física: possibilidades para a formação de professores. Revista Brasileira de Ciências do Esporte, v. 33, n. 3, p. 559-571, 2011.

FLICK, Uwe. Introdução à pesquisa qualitativa. 3. ed. Porto Alegre: Artmed, 2009.

GIL, Antonio Carlos. Métodos e técnicas de pesquisa social. 6, ed. São Paulo: Atlas; 2008.

GILBERT, Wade; TRUDEL, Pierre. Learning to Coach Through Experience: Reflection in Model Youth Sport Coaches. Journal of Teaching and Physical Education, v.21, p. 16-34, 2001.

JARVIS, Peter. Aprendendo a ser uma pessoa na sociedade: Aprendendo a ser Eu. In: ILLERIS, Knud (Org.) Teorias Contemporâneas da Aprendizagem. Porto Alegre: Penso, 2013. p. 31-45.

JARVIS, Peter. Aprendizagem Humana: implícita e explícita. Educação \& Realidade, v.40, n.3, p. 809-825, 2015.

MARINHO, Alcyane; SANTOS, Priscila Mari dos. Hábitos e percepções socioambientais na universidade: Educação Física e Fisioterapia em foco. Revista da Educação Física/UEM, v. 25, n. 3, p. 365-377, 2014.

MALLETT, Clifford et al. Formal vs. Informal Coach Education. International Journal of Sports Science \& Coaching, v.4, n.3, p. 325-64, 2009.

NELSON, Lee J.; CUSHION, Christopher J.; POTRAC, Paul. Formal, Nonformal and Informal Coach Learning: A Holistic Conceptualisation. International Journal of Sports Science \& Coaching, v.1, n.3, p. 247-259, 2006. 
PAIXÃO, Jairo. Entre a aventura e o risco: formação e atuação profissional de instrutores de esporte de aventura no estado de Minas Gerais. Revista Mackenzie de Educação Física e Esporte, v.14, p. 257-271, 2015.

PAIXÃO, Jairo. Training and Professional Performance of Radical Sport Instructors. International Journal of Sports Science, v.3, n.6, p. 198-203, 2013.

PAIXÃO, Jairo; TUCHER, Guilherme. Risco e aventura por entre as montanhas de Minas: a formação do profissional de esporte de aventura. Pensar a Prática, v.13, n.3, p. 1-19, 2010.

PATTON, Michael Quinn. Qualitative evaluation and research methods. 2.ed. Newbury Park: Sage, 1990.

PEREIRA, Adriana Israel de Almeida; SILVA, Flávio José de Lima; SILVA-JÚNIOR, José Martins. Influência dos cursos de capacitação do Projeto Golfinho Rotador na atuação profissional dos condutores de ecoturismo em Fernando de Noronha (PE): uma contribuição a sustentabilidade turística local. Revista Brasileira de Ecoturismo, v.8, n.1, p. 31-58, 2015.

PILETTI, Claudino. Didática Geral. 14.ed. São Paulo: Ática, 1991.

PIMENTEL, Giuliano. Esportes na natureza e atividades de aventura: uma terminologia aporética. Revista Brasileira de Ciências do Esporte, v.35, n.3, p. 687-700, 2013.

RAMOS, Valmor et al. Trajetória de vida de treinadores de surfe: análise dos significados de prática pessoal e profissional. Pensar a Prática, v.17, n.3, p. 815-..., 2014.

RAMOS, Valmor; BRASIL, Vinicius Zeilmann; GODA, Ciro. A aprendizagem profissional na percepção de treinadores de jovens surfistas. Revista de Educação Física/UEM, v.23, n.3, p. 431-442, 2012.

RIBAS, Liz Cristina Camargo; HICKENBICK, Claudia. O Papel de Condutores Ambientais Locais e de Cursos de Capacitação no Ecodesenvolvimento Turístico e as Expectativas Sociais no Sul do Brasil. Turismo em Análise, v.23, n.1, p. 143-165, 2012.

SANTOS, Priscila Mari et al. Formação profissional e percepção de competências de estudantes de Educação Física: uma reflexão a partir da disciplina de esportes de aventura e na natureza.

Revista da Educação Física/UEM, v. 26, n. 4, p. 529-540, 2015a.

SANTOS, Priscila Mari et al. Formação profissional em Educação Física e Fisioterapia: ressonâncias de um projeto de ensino sobre questões socioambientais. Motrivivência, v. 27, n. 46, p. 84-98, 2015b.

SCHÖN, Donald A. Educando o profissional reflexivo: um novo design para o ensino e a aprendizagem. Porto Alegre: Artmed, 2008.

SCHWARTZ, Gisele; CARNICELLI FILHO, Sandro. (Desin)Formação profissional e atividades de aventura: focalizando os guias de "Rafting". Revista Brasileira Educação Física e Esporte, v.20, n.2, p. 103-109, 2006.

STOSZKOWSKI, John; COLLINS, Dave. Sources, topics and use of knowledge by coaches. Journal of sports sciences, v. 34, n. 9, p. 794-802, 2016.

TRUDEL, Pierre; CULVER, Diane; RICHARD, Jean-Paul. Peter Jarvis: Lifelong learning. In: NELSON, Lee; GROOM, Ryan; POTRAC, Paul. Learning in Sports Coaching: Theory and Application. New York: Routledge, 2016. p. 202-214. 
VASCONCELLOS, Hedy Silva Ramos de et al. Educative places for environmental education encouragement. Cadernos Cedes, v. 29, n. 77, p. 29-47, 2009.

VAZ, Jamille Machado et al. Percepção de competências profissionais de instrutores de atividades de aventura na natureza atuantes em Florianópolis (SC). Movimento, v. 23, n. 1, p. 295-310, 2017.

Agradecimentos: Os pesquisadores são gratos à Fundação Museu do Homem Americano (FUMDHAM) e a todos os condutores, funcionários e gestores dos PARNAs do Caparaó e da Serra da Capivara.

\section{Apoio:}

Os pesquisadores agradecem à Coordenação de Aperfeiçoamento de Pessoal de Nível Superior (Capes) e à Fundação de Amparo a Pesquisa do Estado da Bahia (FAPESB) na concessão da bolsa para sua realização. 